\title{
Groundwater investigations in the Hattar industrial estate and its vicinity, Haripur district, Pakistan: An integrated approach
}

\author{
Umair B Nisar ${ }^{1}$, Muhammad J Khan², Muhammad Imran³, Muhammad R Khan ${ }^{4}$, Muhammad Farooq ${ }^{4}$, Siddique \\ A Ehsan ${ }^{3, *}$, Ashfaq Ahmad ${ }^{5}$, Hummad H Qazi ${ }^{6}$, Naim Rashid ${ }^{7}$, Tareq Manzoor ${ }^{8}$ \\ ${ }^{1}$ Centre for Climate Research and Development (CCRD), COMSATS University Islamabad, Pakistan \\ ${ }^{2}$ Dept. of Earth \& Environmental Sciences, Bahria University, Karachi Campus, Pakistan \\ ${ }^{3}$ Dept. of Physics, COMSATS University Islamabad, Lahore Campus, Pakistan \\ ${ }^{4}$ Institute of Geology, University of Azad Jammu and Kashmir, Pakistan \\ ${ }^{5}$ Dept. of Computer Sciences, COMSATS University Islamabad, Lahore Campus, Pakistan \\ ${ }^{6}$ Innovative Eng. Research Alliance, University Teknologi, 14 Malaysia, Malaysia \\ ${ }^{7}$ Dept. of Chemical Engineering, COMSATS University Islamabad, Lahore Campus, Pakistan \\ ${ }^{8}$ Energy Research Centre, COMSATS University Islamabad, Lahore Campus, Pakistan \\ *Corresponding Author: siddiqueaehsan@cuilahore.edu.pk
}

\begin{abstract}
The Hattar industrial estate in the Haripur district, Khyber Pakhtunkhwa (KPK), Pakistan, is investigated for the groundwater potential and aquifer vulnerability using vertical electrical sounding (VES) data, borehole logs, and hydrochemical analysis. A total of eight VES points were acquired in the Haripur region using Schlumberger configuration. The interpreted VES models are further constrained by four borehole logs to delineate comprehensive information of the thin lithological layers, subsurface layers configuration, and spatial extent in the area. A quantitative interpretation based on the VES and the borehole data suggests six main subsurface layers: (i) soil cover, (ii) gravel, (iii) clay, (iv) clay with gravel, (v) silty-clay, and (vi) sand with a boulder in the study area. A fence diagram is also generated to provide a detailed paleo-depositional model of the subsurface layers. The interpreted VES data is utilized to compute aquifer thickness, longitudinal conductance, and transverse resistance within the study area. The lateral extent and protective capacity for the aquifer were inferred from these measurements. The aquifer thickness is relatively low in the central and eastern parts ranging from $10 \mathrm{~m}$ to $11 \mathrm{~m}$. The longitudinal conductance map shows values greater than 2 mhos from the central region to northern one. This is indicative of moderate to good protective capacity for the aquifer and is less vulnerable to infiltration of Hattar industrial polluted fluid. However, the values less than 0.19 mhos in the southwest and east are indicative of weak protective capacity with the risk of contamination. The hydrochemical analysis of the surface and subsurface water is carried out at eleven locations to identify the water quality within the study area. The chemical analysis of the water shows the presence of a high concentration of magnesium, bicarbonate, and chlorine away from the World Health Organization (WHO) standard.
\end{abstract}

Keywords: Apparent resistivity; borehole; groundwater; hydro-chemical analysis; vertical electrical sounding.

\section{Introduction}

The Indus plain, starting from the Himalayan foothills to the Arabian Sea, supports most of the groundwater resources in Pakistan. The groundwater is mainly stored in alluvial deposits. Several studies have been carried out to evaluate the groundwater quality in Pakistan (Niaz et al., 2015). The study area lies in Haripur district, which is located about $80 \mathrm{~km}$ northwest of Islamabad (Figure1). After the establishment of the Hattar industrial estate (HIE) in 1970, the population growth in the area demanded an increase in the clean water supply for domestic and industrial use. The area within and in the vicinity of HIE is facing water problems including low quality of surface water resources, continuous shortage of good quality groundwater, and contamination of groundwater from industrial waste from rubber, ghee, cement, ceramic, and leather industries situated in HIE. The geoelectrical methods are widely used to investigate potential groundwater subsurface strata and groundwater contamination (Kelly \& Stanislav, 1993; Nazaruddin, 2015; Adesola et al., 2017). The apparent resistivity of soil and subsurface lithologies is measured as a function of depth with the VES method. A reasonable relationship 
between geological structure and groundwater resources is determined by this method. The hydraulic parameters of aquifers are estimated by the concept of Dar-Zarrouk parameters (Maillet, 1947). The Dar-Zarrouk concept is further applied to estimate the protective capacity of groundwater, transmissivity, and lateral extent of the subsurface lithologies (Ezeh, 2011).

The hydrochemical analysis of surface and groundwater samples was carried out for major ions and trace elements (Freeze and Cherry, 1979; AlSulaimi and Al-Ruwaih, 2004). The total hardness of water is also considered in the hydrochemical analysis to check the presence of calcium and magnesium concentrations. This is the first research effort in the Haripur region to delineate subsurface water potential by using geophysical, geological, and hydrochemical methods. The analysis of these data sets enables us (i) to significantly identify the groundwater bearing strata, its lateral and vertical extent, (ii) to identify the protective capacity of the aquifer, and (ii) to delineate the quality of the surface and groundwater. This improved dataset can serve as a benchmark for further geophysical and geological investigations, which in turn will benefit the local community suffering from serious issues related to quality water.

\section{The study area}

The Haripur district is located about $80 \mathrm{~km}$ northwest of Islamabad in the province of Khyber Pakhtunkhwa (Figure 1). The area covers about $1725 \mathrm{~km}^{2}$ that includes about $460 \mathrm{~km}^{2}$ of mountains at an altitude of $532 \mathrm{~m}$ along Karakoram Highway. The Dor and Haro rivers are the main rivers of the Haripur, which are recharged by the melting snow, rainfall, and groundwater (Figure 1). The stratigraphy of the Haripur region consists of Alluvium, Kuldana Formation, Chorgali Formation, Margalla Hill Limestone, Patala Formation, Lockhart Formation, Hangu Formation, Kawagrah Formation, Lumshival Formation, Data Formation, Abbottabad Formation, and Hazara slates from recent to Pre-Cambrian times (Latif, 1970a). The study area is bounded in the north to the northeast by Nathiagali Hissartang Block, in the west by Attock Cherat ranges, in the east by Margalla hills, and in the west by Gandghar ranges. The exposed rocks in the study area are mainly sedimentary and metamorphic origin (Figure 1).
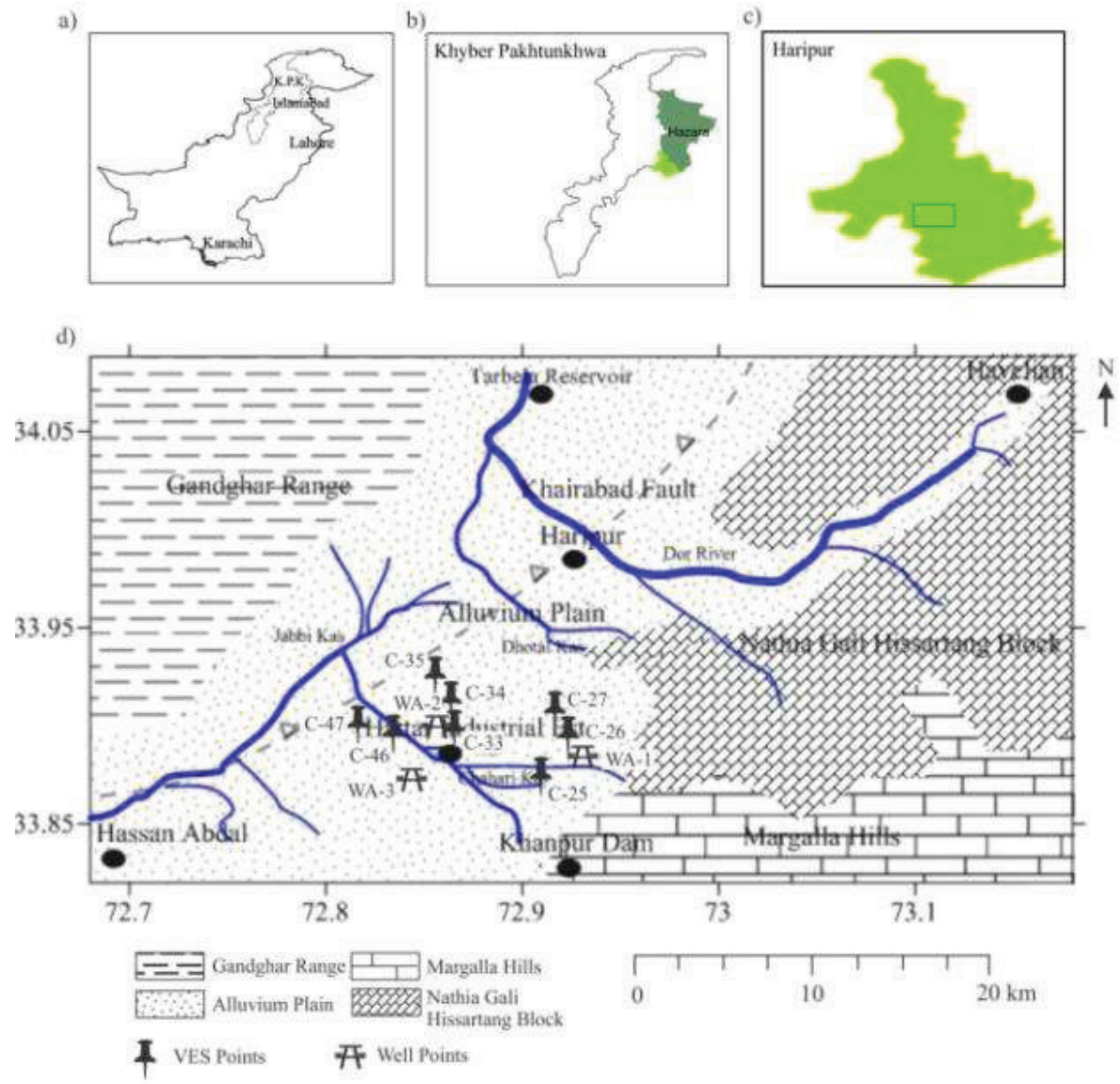

Fig. 1. (a), (b), and (c) Map of Pakistan, Khyber Pakhtunkhwa province, and Haripur region. The study area is highlighted with black rectangle. (d) Geological map of the study area (modified after Umair et al., 2018). 


\section{Materials and methods}

The resistivity techniques, especially the vertical electrical sounding (VES) method, are largely used worldwide for investigating resistive layer properties, groundwater potential, and aquifer studies (Muchingami et al., 2012). The VES survey was carried out by using an ABEM SAS 300c Terrameter with Schlumberger electrode configuration across the Hattar industrial estate and its vicinity (Figures 1 and 2). The system is connected to 4 electrodes, which were laid out in a straight line (Figure 2).

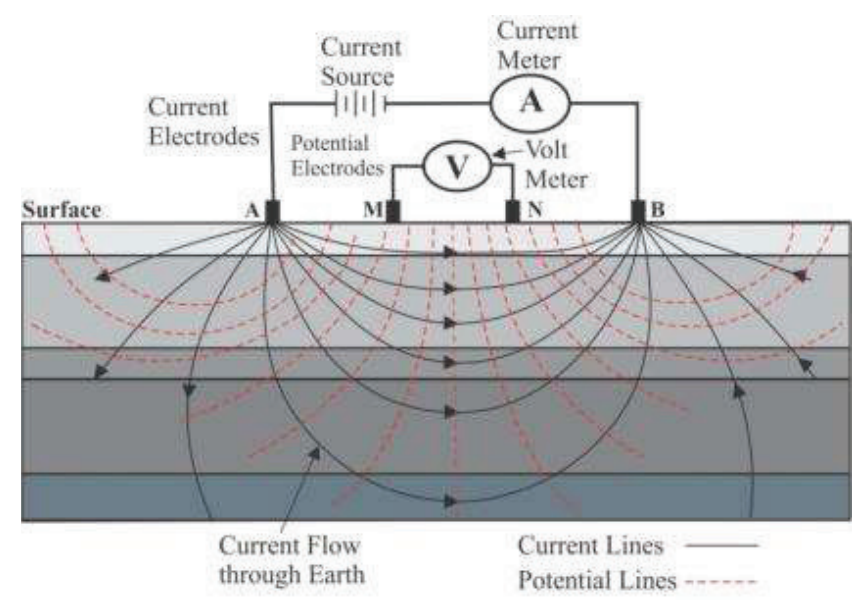

Fig. 2. Schematic illustration of the basic measurements using electrical resistivity method (Modified after J.A. Clark et al., 2011). Solid black lines represent current flow through layered subsurface structure. Dashed red line represents contoured electrical potential.

By increasing the spacing between the current electrodes, the depth of current penetration increases, which allows for a deeper depth of investigation. The depth of sounding resulted in the apparent resistivity $\left(\rho_{\mathrm{a}}\right)$ measurement as a function of current passed into the ground, voltage drop between electrodes, and current intensity. The relationship between electrical and hydraulic parameters is to calculate the hydraulic parameters such as longitudinal conductance (S) and transverse resistance (T) (Okonkwo \& Ezeh, 2012). The hydraulic parameters derived from the apparent resistivity $\left(\rho_{\mathrm{a}}\right)$ and thickness are given as:

Longitudinal conductance

$\mathrm{S}=\mathrm{h} / \rho_{\mathrm{a}}$

Transverse resistance

$\mathrm{T}=\mathrm{h} \cdot \rho_{\mathrm{a}}$ where $\mathrm{h}$ represents thickness and resistivity of the subsurface layer. The water samples were collected from surface streams and wells. A total of eleven water samples were collected for the hydrochemical analysis. This analysis allowed the correlation between VES data and the water samples. Three samples from each location, about $60 \mathrm{ml}$ each, were collected in plastic high-density polyethylene bottles (HDPE); one of these samples were acidified for trace elements. The collected samples were then analysed by using an atomic absorption spectrometry instrument.

\section{Results and discussion}

For this paper, we are presenting results from two VES points (Figures $3 \mathrm{a}$ and $3 \mathrm{~b}$ ). The results indicate the presence of five to six subsurface layers with different thicknesses and lithologies (Table 1). The lithologies of the subsurface layers are inferred from the resistivity model (Table 1) and constrained by the available borehole data in the study area. The resistivity values range from 10 to $363 \Omega \mathrm{m}$ for the gravel layer containing groundwater (Figures 3a, 4b, and 4c). Three aquifer layers are present across the VES points C-25 to C-27 (Figure 4a). For the mapping purpose, we have utilized the thickness of the aquifer, about $60 \mathrm{~m}$ deep.

\subsection{Geological analysis:}

The lithological information obtained from the three boreholes (WA-1, WA-2, and WA-3, Figure 1) is used to constrain the lithological model generated from the resistivity data. Based on the resistivity inferred lithological model and borehole data, three cross-sections (A-A', B-B', and C- C') are prepared (Figures 4a, 4b, and $4 c)$. The cross-section A-A' is generated from the three VES points (C-25, C-26, and C-27) and a single borehole (WA-1, Figure 4a). The cross-section A-A' represents the presence of four lithologies (top soil, gravel, clay with gravel, and clay). The groundwater accumulation is evident in three gravel layers; however, the middle gravel layer, about $35 \mathrm{~m}$ deep, is partially capped by clay with gravel layer (Figure 4a). This semi-confined aquifer is about $11 \mathrm{~m}$ thick, and its continuation towards west is not evident from the borehole and resistivity data (Figures $3 \mathrm{~b}$ and $4 \mathrm{~b}$ ). The bottom gravel layer is about $50 \mathrm{~m}$ deep, and it is capped by a $5 \mathrm{~m}$ thick clay layer. This confined aquifer is about $10 \mathrm{~m}$ thick, and it is underlain by impermeable clay layer. The confined aquifer extends towards west, which is evident from the borehole and resistivity data (Figures $3 b$ and $4 b$ ). 
The cross-section B-B' is generated from the three VES points (C-33, C-34, and C-35) and a single borehole (WA-2, Figure 4b). The cross-section B-B' shows the presence of four lithologies (top soil, silty clay, gravel, and clay). The top layer of gravel is about $25 \mathrm{~m}$ deep and 5 $\mathrm{m}$ thick. The cross-section $\mathrm{C}-\mathrm{C}^{\prime}$ is generated from the two VES points (C-46 and C-47) and a single borehole (WA-3, Figure 4c). The cross-section C-C' shows the presence of four lithologies (top soil, silty clay, sand with boulder, and clay and boulder alternating layers). The massive body of sand with boulder is present at two different levels (Figure 4b). The massive body of sand with boulder is present at two different levels (Figure 4c). The top sand with the boulder layer is about $20 \mathrm{~m}$ deep and $30 \mathrm{~m}$ thick. The bottom sand with the boulder layer is about $60 \mathrm{~m}$ deep. The bottom aquifer is confined, and it is correlated with the gravel layer present in cross-sections A-A ' and B-B'. It is ensured that the correlated sections are at the same depths (Figures 5a and 5b).
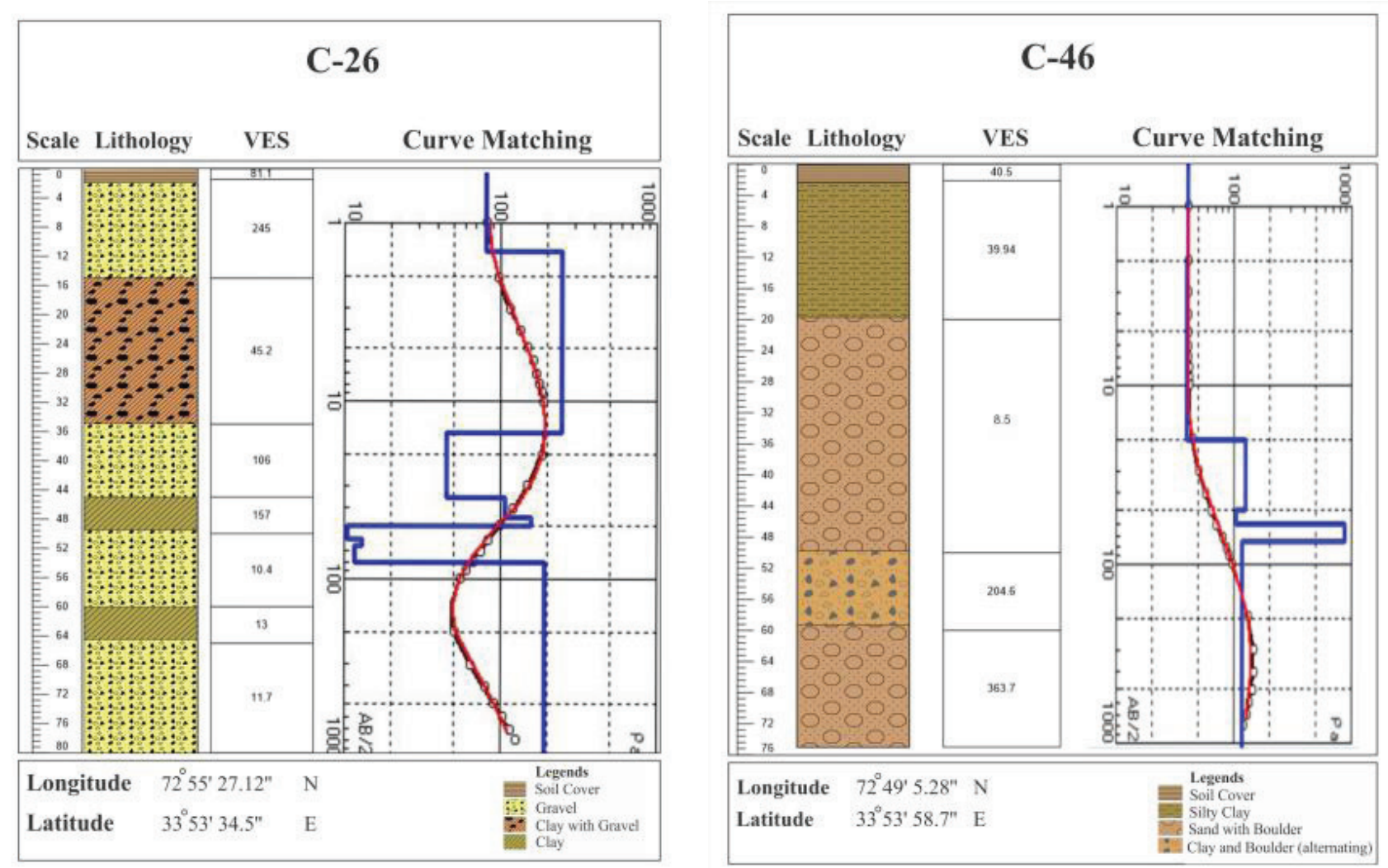

Fig. 3. (a) Vertical electrical sounding (VES) points 26. The resistivity model represents the number of subsurface layers and inferred lithologies with thicknesses. (b) Vertical electrical sounding (VES) point 33. The resistivity model represents the number of subsurface layers and inferred lithologies with thicknesses.

Table 1. Interpreted subsurface geology.

\begin{tabular}{llll}
\hline $\begin{array}{l}\text { Layer } \\
\text { number }\end{array}$ & $\begin{array}{l}\text { Interpreted } \\
\text { thickness }(\mathrm{m})\end{array}$ & $\begin{array}{l}\text { Resistivity } \\
\text { range }(\Omega \mathrm{m})\end{array}$ & $\begin{array}{l}\text { Interpreted } \\
\text { lithology }\end{array}$ \\
\hline 1 & $2-3$ & $21-81$ & Loose dry soil \\
2 & $5-16$ & $8-245$ & Gravel \\
3 & $5-10$ & $11-157$ & Clay \\
4 & $18-20$ & $23-45$ & Clay with gravel \\
5 & $16-40$ & $16-52$ & Silty clay \\
6 & $16-30$ & $126-876$ & Sand with boulder \\
7 & $10-12$ & $104-205$ & Clay with boulder \\
\hline
\end{tabular}




\subsection{Aquifer thickness:}

The interpretation of resistivity and borehole datasets indicates the presence of five to seven subsurface layers. These layers constitute a total thickness of about $90 \mathrm{~m}$ in the subsurface (Table 1). The gravel layers are present at three different depths with resistivity values ranging from 10 to $360 \Omega \mathrm{m}$. The groundwater accumulation in the gravel layers is evident at various locations in the region. The bottom gravel layer, present at about $62 \mathrm{~m}$ depth, indicates the characteristics of confined aquifer as it is well-capped by impermeable clay layer (Figures 4a, $4 b$, and $4 c$ ). A thickness map of this confined aquifer is generated across the study area (Figure 5). The aquifer thickness map shows a thickness variation from 10 to 17 $\mathrm{m}$. An increase in the aquifer thickness is evident from the east to towards the west (Figure 5).

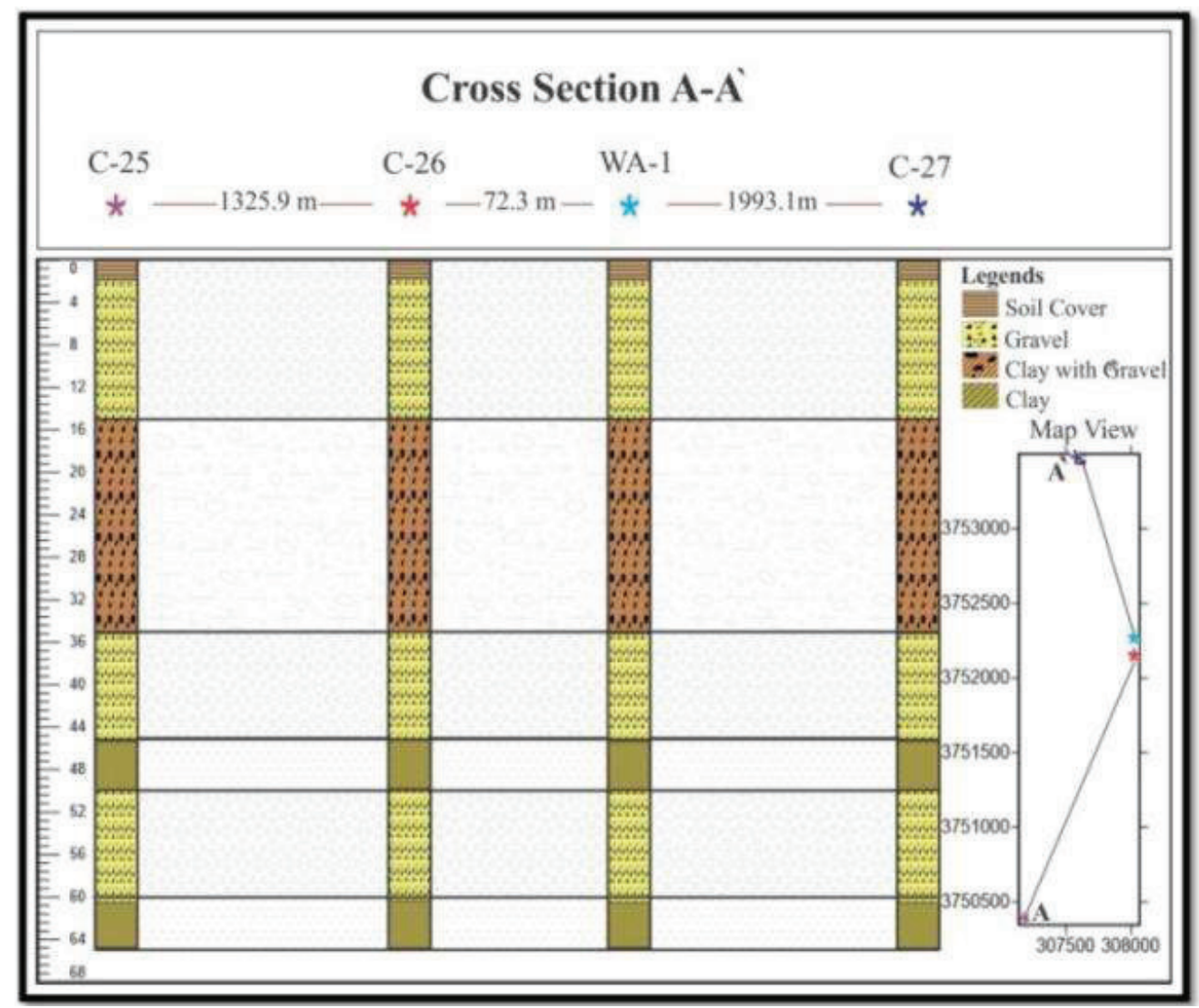

Fig. 4 (a). Cross-section A-A shows correlation between three VES points (C-26, C-27, and C-28) and one borehole (WA-1).

Table 2. Longitudinal conductance and protective capacity rating (modified after Henriet 1976).

\begin{tabular}{ll}
\hline $\begin{array}{l}\text { Longitudinal } \\
\text { conductance (mhos) }\end{array}$ & $\begin{array}{l}\text { Protective } \\
\text { capacity rating }\end{array}$ \\
\hline $0>10$ & Excellent \\
$5-10$ & Very good \\
$0.7-4.9$ & Good \\
$0.2-0.69$ & Moderate \\
$0.1-0.19$ & Weak \\
$<0.1$ & Poor \\
\hline
\end{tabular}




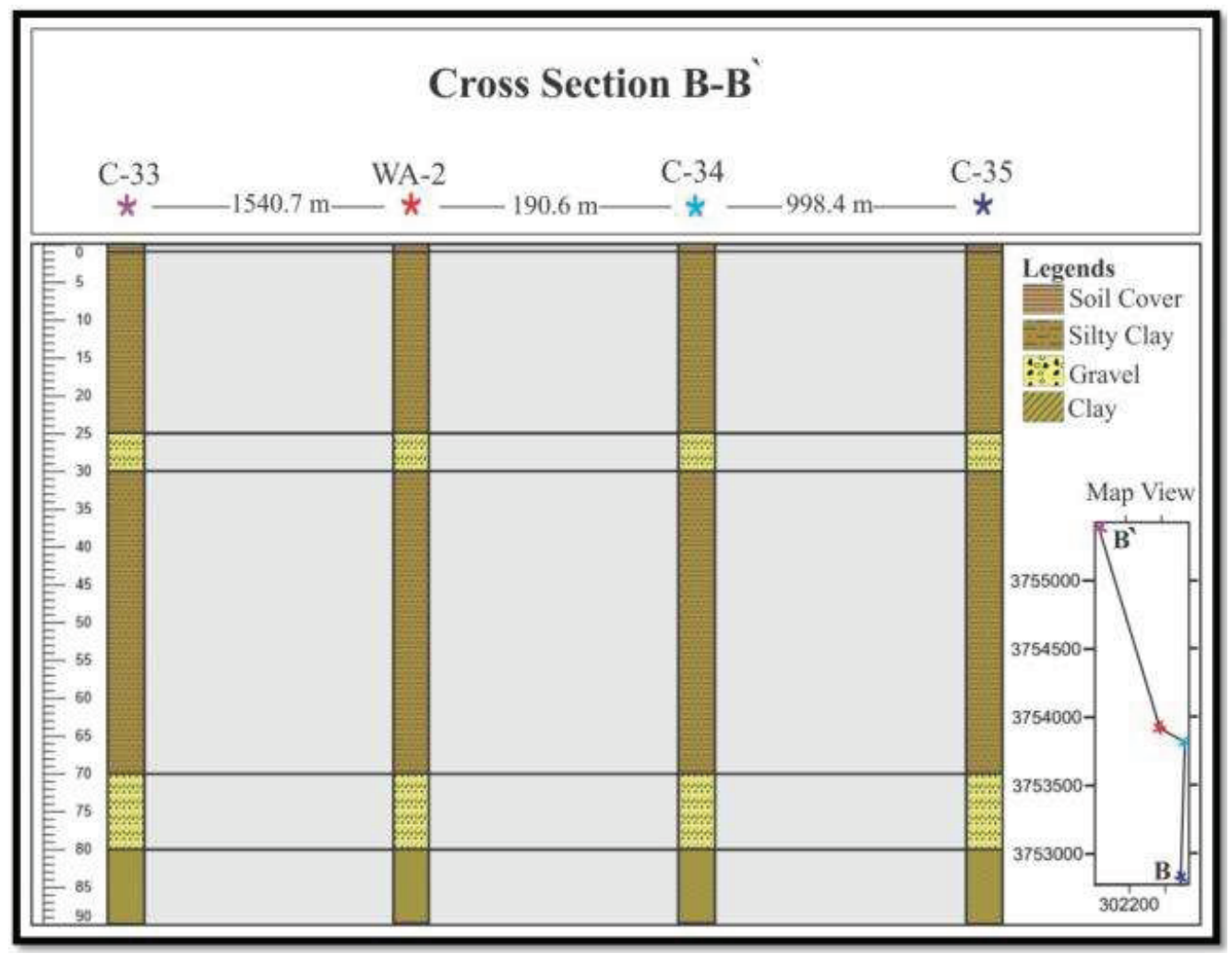

Fig. 4 (b). Cross-section B-B shows correlation between three VES points (C-33, C-34, and C-35) and one borehole (WA-2).

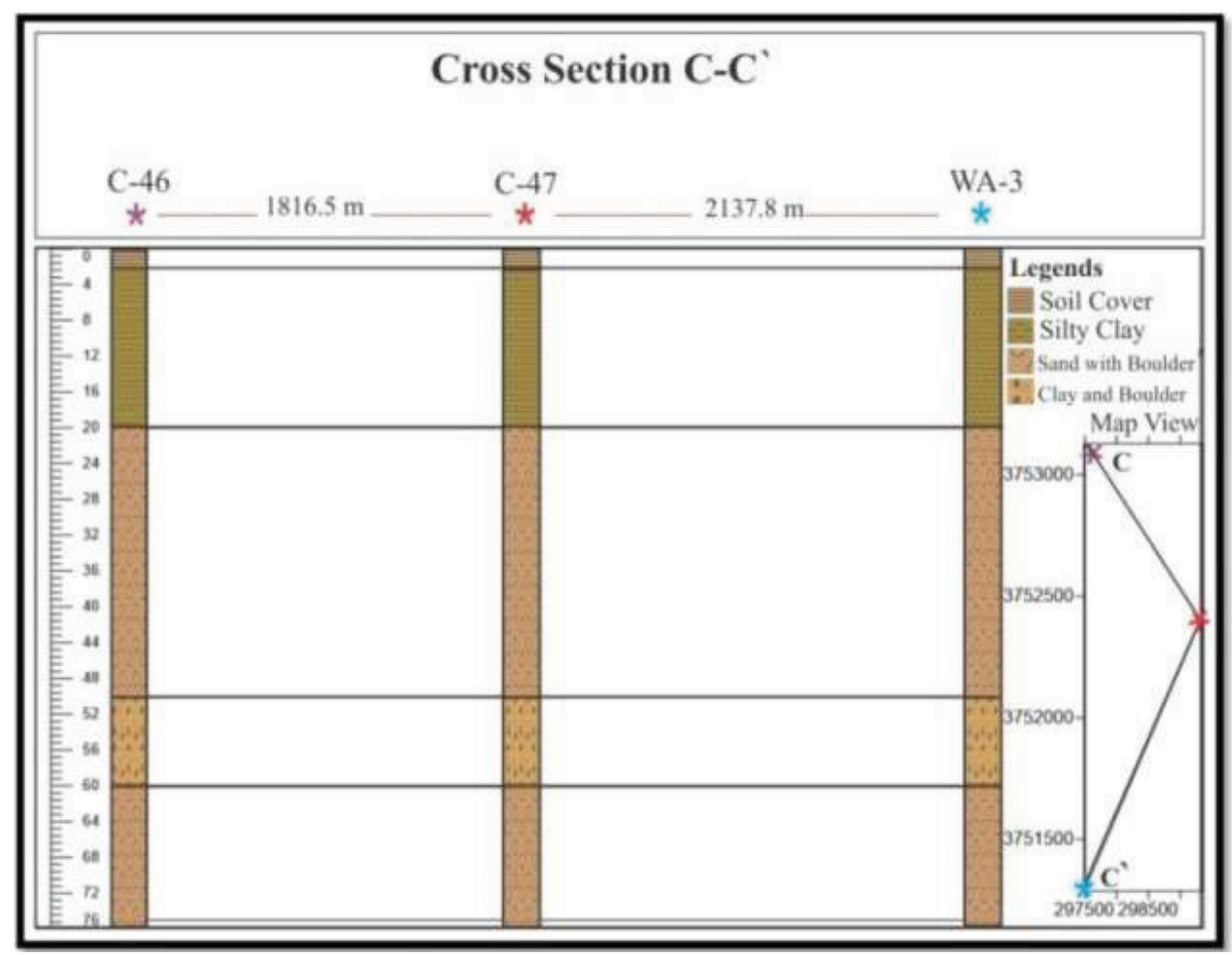

Fig. 4 (c). Cross-section C-C shows correlation between three VES points (C-46 and C-47) and one borehole (WA-3). 


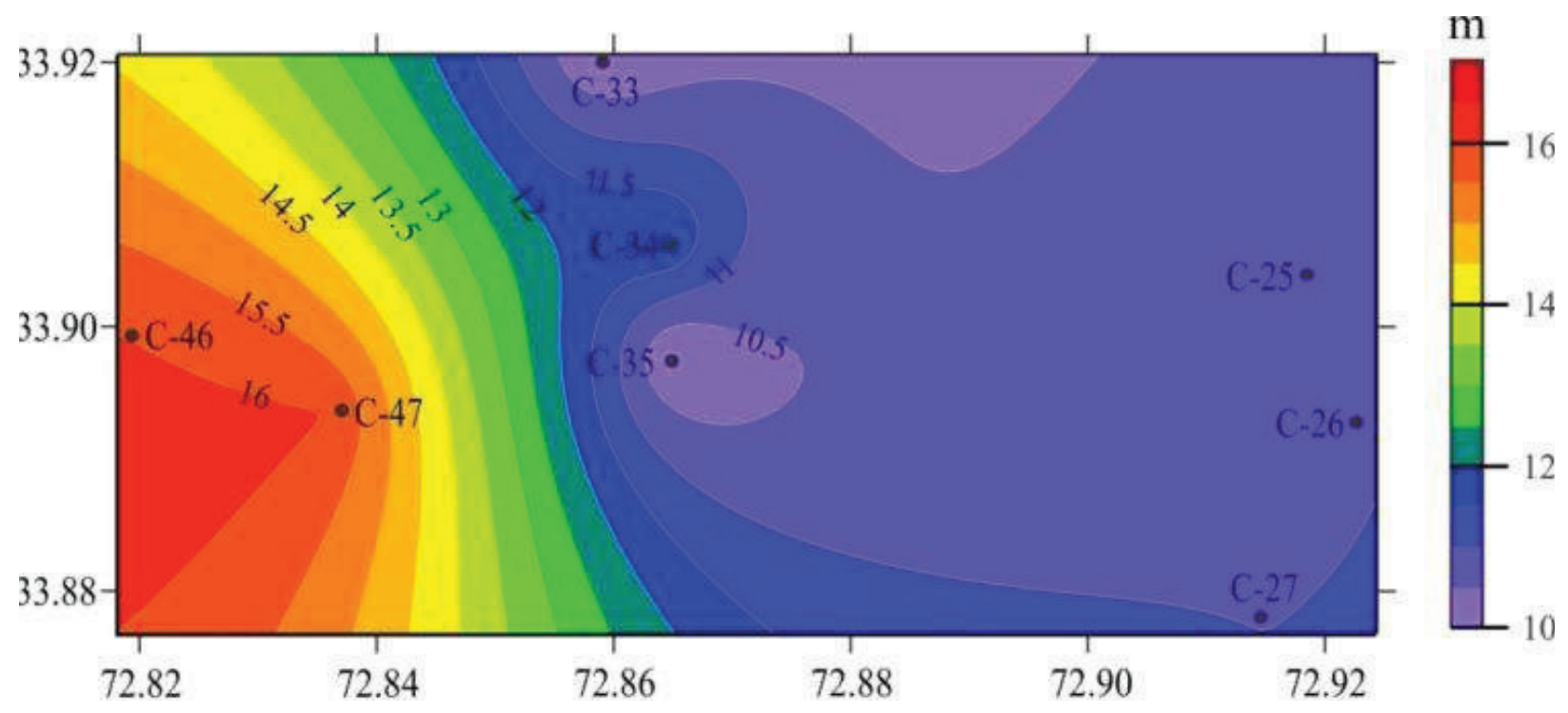

Fig. 5. Aquifer thickness map of the region showing an increase in the thickness in the west and northwest. The black dots represent electrical resistivity sounding locations.

\subsection{Hydraulic parameters:}

The hydraulic parameters that include longitudinal conductance and transverse resistance are measured to analyse the protective overburden of the aquifer. The subsurface layers such as impermeable clay layers above the aquifer act as an overburden protection. These layers may filter or retard the percolating fluids (Mogaji et al., 2007; Mohammad et al., 2016). The longitudinal conductance map and transverse resistance map (Figures $6 \mathrm{a}$ and $6 \mathrm{~b}$ ) are generated for the aquifer at about $60 \mathrm{~m}$ deep overburden clay layers.

These maps were helpful to determine regions with higher groundwater potential and good protective capacity. Table 2 shows modified longitudinal conductance and protective capacity rating for the study area (Henriet, 1976). The longitudinal conductance map (Figure 6a) generated for the overburden clay layers shows a range of values from 0.045 to 2.41 mhos. It shows an increasing trend from south to north and a decreasing trend from the central region to east and west. The transverse resistance map (Figure $6 \mathrm{~b}$ ) for the overburden clay shows a decreasing trend from the west to east and values ranging from 350 to $2600 \mathrm{ohm} \cdot \mathrm{m}^{2}$ in the central region to east and west.
The transverse resistance map (Figure 6b) for the overburden clay shows a decreasing trend from the west to east and values ranging from 350 to $2600 \mathrm{ohm} . \mathrm{m}^{2}$. The highest values of the transverse resistance are concentrated in the west. The central region shows values from 600 to $1100 \mathrm{ohm} \cdot \mathrm{m}^{2}$. Based on the longitudinal conductance map (Figure 6a), the aquifer can be classified into three zones of protective capacity; 1) north and central regions show good protective capacity with values ranging from 0.7 - 4.9 mhos; 2) the southern region can be rated as a moderate protective capacity zone with values ranging from 0.2 to 0.69 mhos; and 3) the eastern and western regions show values from 0.04 to 0.1 mhos, rated as having a weak to poor protective overburden capacity.

\subsection{Hydrochemical analysis:}

The water chemistry analyses (Table 3 ) were carried out to identify and quantify the chemical components of the water samples collected from three streams and eight wells. 


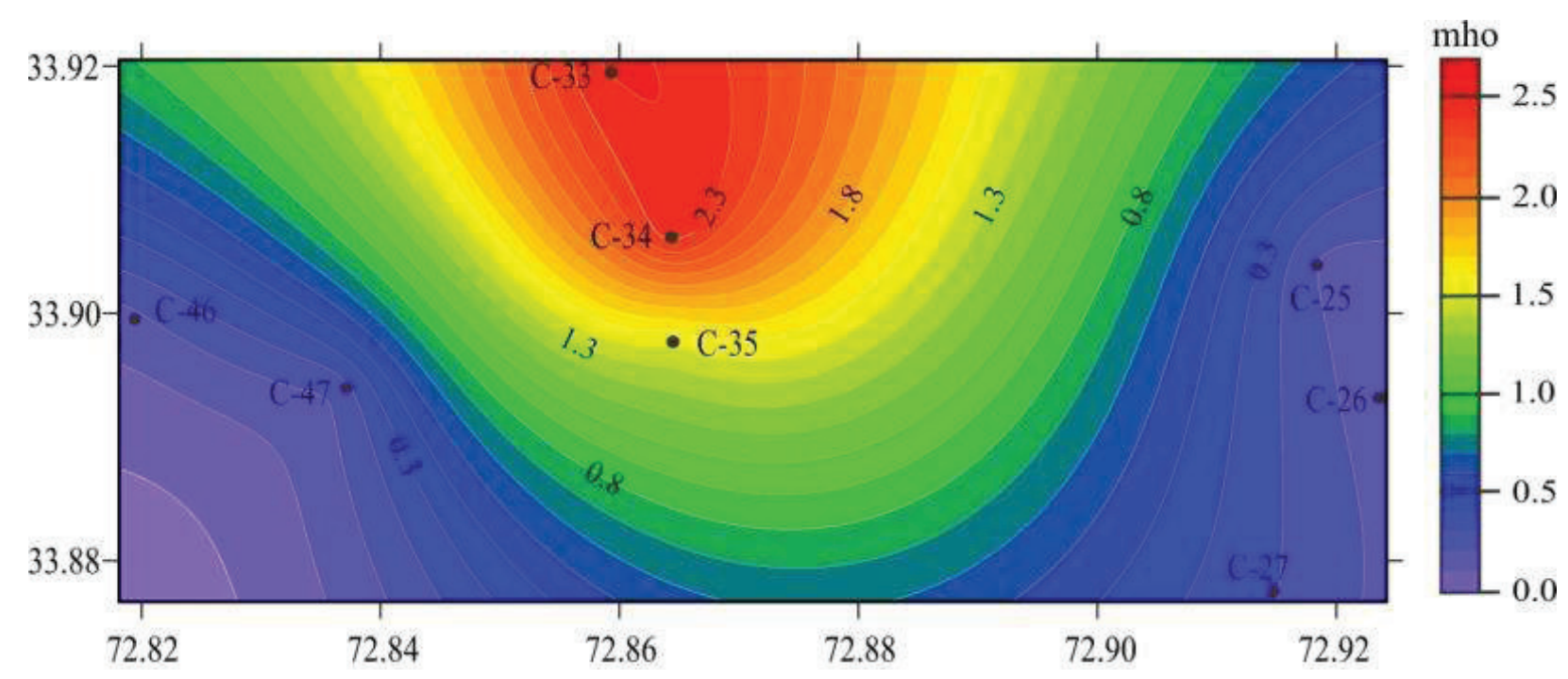

Fig. 6 (a). Longitudinal conductance calculated for the overburden layer in the region. The black dots represent electrical resistivity sounding locations.

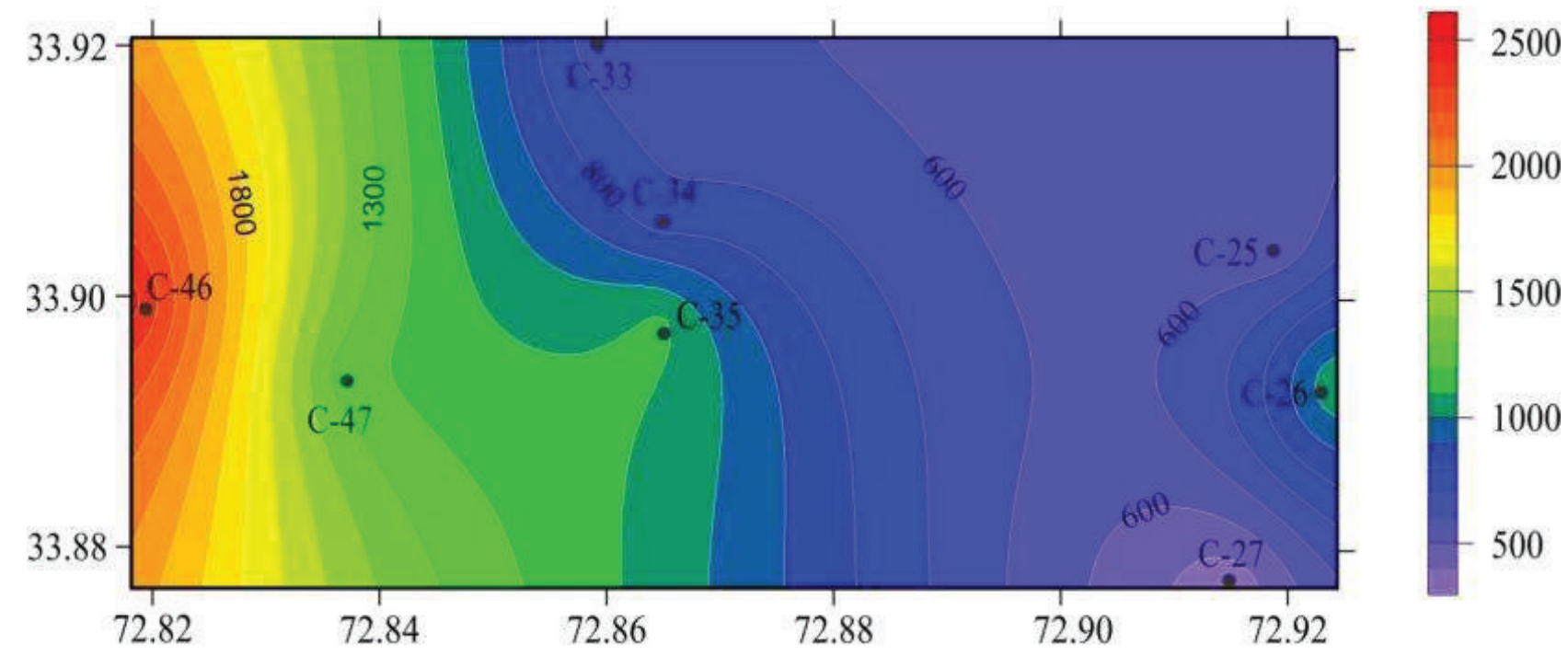

Fig. 6 (b). Transverse resistance calculated for the overburden layer in the region. The black dots represent electrical resistivity sounding locations.

The wells were about 120 feet deep in the study area. The total dissolved solids (TDS) are higher at surface levels (S1, S4, and S3) than the permissible limit (500 $\mathrm{mg} / \mathrm{L}$ ). The total hardness (TH) is also high in all water samples except subsurface sample (SS2). The TH in S1, $\mathrm{S} 2$, and S3 is much higher than the permissible limit. The high value of the TH may correspond to high TDS at the surface level. The TH is mainly because of calcium (Ca) and magnesium $(\mathrm{Mg})$, which contribute to carbonate hardness. The concentration of $\mathrm{Mg}$ is much higher than the $\mathrm{Ca}$ in almost all the water samples. The higher concentrations of $\mathrm{Mg}$ in $\mathrm{S} 1, \mathrm{~S} 2$, and $\mathrm{S} 3$ correspond to high TDS and TH. In non-carbonate hardness, which is due to chlorine $(\mathrm{Cl})$ and sulphate (SO4), chlorine concentration is much higher than the sulphate. Thus, $\mathrm{Cl}$ is the major element, which contributes to non-carbonate hardness. The analysis of carbonate and bicarbonate further clarifies that the concentration of carbonate was negligible, and thus, not detected; it provides an understanding that the hardness is due to bicarbonate. The electrical conductivity (EC) measurements show that it is in good agreement with TDS and TH. The water $\mathrm{pH}$ in all samples is closer to the neutral (7.0), which is acceptable. The water quality at surface and subsurface is mainly deteriorated by the $\mathrm{Mg}$, bicarbonate, and $\mathrm{Cl}$ present in high dissolved concentrations in the study area. 
Table 3. Results of hydrochemical analysis of water samples (surface and subsurface) taken from the study area.

\begin{tabular}{|c|c|c|c|c|c|c|c|c|c|c|c|c|}
\hline Parameter & S1 & $\mathrm{S} 2$ & S3 & SS1 & $\mathrm{SS} 2$ & SS3 & SS4 & SS5 & SS6 & SS7 & SS8 & WHO/EU/Canada \\
\hline $\mathrm{EC}(\mu \mathrm{S} / \mathrm{cm})$ & 1.15 & 1.23 & 1.34 & 0.69 & 0.53 & 0.71 & - & - & - & - & - & $0.05-0.5$ \\
\hline $\mathrm{pH}$ & 7.15 & 7.01 & 7.30 & 7.48 & 7.38 & 7.26 & - & - & - & - & - & $6.5-8.5$ \\
\hline Calcium* & 285 & 231 & 285 & 138 & 113 & 176 & - & - & - & - & - & $<200$ \\
\hline Chloride* & 220 & 55 & 260 & 35 & 30 & 50 & - & - & - & - & - & $<250$ \\
\hline $\mathrm{TH}^{*}$ & 820 & 800 & 810 & 500 & 430 & 580 & - & - & - & - & - & $<500$ \\
\hline Calcium C.* & 714 & 557 & 714 & 346 & 283 & 441 & - & 一 & - & - & - & $<500$ \\
\hline Magnesium* & 645 & 660 & 636 & 415 & 360 & 472 & - & - & - & - & - & $<50$ \\
\hline Sulphur Oxide & 8 & 10.3 & 28 & 12.8 & 9.6 & 10 & - & - & - & - & - & $<250$ \\
\hline Nickel** & - & - & - & - & - & 一 & 11.5 & 7.9 & 9.55 & 10 & 9.7 & $<20$ \\
\hline Ferric** & - & - & - & - & 一 & 一 & 3.2 & & & 1.59 & 5.02 & $<0.2-0.3$ \\
\hline TDS** & 805 & 897 & 930 & 474 & 348 & 460 & - & - & - & - & - & $<500$ \\
\hline
\end{tabular}

WHO, World Health Organization; EU, European Union; S, Surface sample; SS, Subsurface sample (about 120 feet deep $) ; *,(\mathrm{mg} / \mathrm{L}) ; * *,(\mu \mathrm{g} / \mathrm{L})$

4.5 Correlation between VES and hydrochemical analysis:

The VES dataset provides indirect measurements of the subsurface anomalies (Muchingami et al., 2012). The availability of other datasets such as borehole logs, pumping data, and hydrochemical data can place strong constraints on the results by the VES dataset. In the present study, the VES and borehole datasets are correlated with hydrochemical analysis of the water samples collected from eleven surface and subsurface locations. The higher electrical conductivities are associated with impurities present in the water that would increase conductivity (Niaz et al., 2018). The vulnerability mapping (Figures 8a and $8 \mathrm{~b}$ ) indicates clay starved zones towards the eastern, central, and western parts. The starved zones are dominated by coarser lithologies with high permeability, which can transmit the surficial contaminants to shallow subsurface aquifer. The low resistivity values observed in the shallow aquifer (Tables 1 and 2) also suggest the presence of impurities in these layers. The hydrochemical analysis of water samples show higher electrical conductivity, $\mathrm{Mg}$, $\mathrm{Cl}$, and $\mathrm{TH}$ for surface and subsurface water samples, which are indicative of low water quality (Table 3).

\section{Conclusions}

In the study area, the surface and groundwater are contaminated by the wastes excreted from industries. The objective of this study is to evaluate the shallow subsurface water potential and quality using a combination of VES, borehole data, and hydrochemical data. The integrated geological and VES techniques proposed six subsurface lithologies with difference thicknesses and lateral extending. The survey reveals a couple of productive groundwater zones in the study area. However, the aquifer, present at about $60 \mathrm{~m}$ deep, shows continuous lateral extension and assures adequate drinkable water resource in the study area. The aquifer thickness map shows an increase in thickness from east to west. The hydraulic parameters investigated the groundwater potential and vulnerability of the aquifer. The entire study area can be classified into zones of good to poor protective capacity. The overburden protective capacity of aquifer in the north, central, and southern regions is good to moderate. The eastern, central, and western regions of the study area are highly vulnerable to the infiltration of dumped wastes from the industries. The hydrochemical analysis of the surface and borehole water reveals the presence of contaminants. The high concentrations of magnesium, bicarbonate, and chlorine are the major elements, which cause high dissolved concentration and deteriorate the water quality.

\section{References}

Adesola, A.M., Ayokunle, A.A. \& Adebowale, A.O. (2017). Integrated geophysical investigation for pavement failure along a dual carriage way. Southwestern Nigeria: a case study. Kuwait Journal of Science, 44(4). 
Al-Sulaimi, J.S. \& Al-Ruwaih, F.M., (2004). Geological, structural and geochemical aspects of the main aquifer systems in Kuwait. Kuwait Journal of Science and Engineering, 31(1): 149-174.

Clark, J.A. \& Page, R. (2011). Inexpensive geophysical instruments supporting groundwater exploration in developing nations, Journal of Water Resource and Protection, 3: 768-780.

Ezeh, C.C. (2011). Geoelectrical studies for estimating aquifer hydraulic properties in Enugu State. Nigeria. Int. J. physical sci. 6: 3319-3329.

Freeze, R.A. \& Cherry, J.A. (1979). Groundwater, Prentice Hall, Englewood Cliffs.

Henriet, J.P. (1976). Direct application of the Dar Zarrouk parameters in groundwater surveys. Geophysical Prospecting, 24; 344-353.

Kelly, W.E. \& Stanislav, M. (1993). Applied Geophysics in Hydrogeological and engineering practice, Elsevier Amsterdam, 292.

Latif, M.A. (1970a). Explanatory notes on the geology of southern Hazara to accompany the revised geological map. Wein Jahrb. Geol. B. A; Sonderb, 15: 5-20.

Maillet, R. (1947). The fundamental equations of electrical prospecting”. Geophysics, 12: 529-556.

Mogaji. K.A., Adiat, K.A.N. \& Oladapo, M.I. (2007). Geoelectric investigation of the Dape Phase 111 Housing Estate FCT Abuja Northcentral Nigeria. Online Journal of Earth Science, 1, 76-84.

Mohammad, A.H. \& Odeh, T. (2016). A modified modeling of potentiality and vulnerability of the groundwater resources in Amman Zarqa Basin. Jordan. Kuwait Journal of Science, 43(1).

Muchingami, I., Hlatywayo, D.J. \& Chuma, C. (2012). Electrical resistivity survey for groundwater investigations and shallow subsurface evaluation of the basaltic-greenstone formation of the urban Bulawayo Aquifer. Phys. Chem. Earth 50-52:4451.http://dx.doi. org/10.1016/j.pce.2012.08.014.

Nazaruddin, D.A., Amiruzan, Z.S., Hussin, H. \& Jafar, M.T. (2017). Integrated geological and multi-electrode resistivity surveys for groundwater investigation in Kampung Rahmat village and its vicinity, Jeli district, Kelantan, Malaysia. Journal of Applied Geophysics, 138: 23-32.

Niaz, A., Khan, M.R., Mustafa, S. \& Hameed, F. (2015).
Determination of aquifer properties and vulnerability mapping by using geoelectrical investigation of parts of Sub-Himalayas, Bhimber, Azad Jammu and Kashmir, Pakistan. QJEGH, 49: 1-3.

Okonkwo, A.C. \& Ezeh, C.C., (2013). Aquifer hydraulics and delineation of groundwater quality zones using Electrical resistivity method at Oduma and environs in Enugu state, Southeastern Nigeria. J . Geol . Min. 3(1): 31-39.

Umair, N., Khan, R., Khan, S., Farooq, M., Rizwan, M., Ashfaq, K.A., Razzaq, S.S. \& Abrar N., (2018). Quaternary paleo-depositional environment in relation with groundwater management of Hazara basin, SubHimalayas, Pakistan: A blend of Geophysical and Geological techniques. Journal of Himalayan Earth Sciences, 51: 99-112.

Submitted : 08/05/2019

Revised : 24/11/2019

Accepted : 25/12/2019

DOI : 10.48129/kjs.v48i1.7820 